\title{
A imagem como metáfora do desejo
}

\author{
Alvaro de Pinheiro Gouvêa'
}

\begin{abstract}
RESUMO
A questão da imagem e da midia nos leva à necessidade de um suporte de imagem no qual o invisivel (o objeto idéia) e o visivel (o objeto concreto) formam uma unidade medial em busca de um sentido. $O$ "objeto idéia" é um lugar virtual de verdade e a "metáfora sensorial" é a identidade de uma humanidade solta do elemento de fascinação exercido sobre nós pela confrontação entre a "imagem idéia", a "imagem fantasma" e o objeto concreto. As "metáforas sensoriais" são estocadas de maneira visivel no "Ateliê de Imagens", qualquer que seja seu enquadramento. A imagem fantasma sai de uma matriz virtual (o Ateliê Intimo) obrigando os fantasmas e idéias a desenvolver novas modalidades de percepção e reagir a novas técnicas de representação. No "ateliê de imagens", o objeto concreto serve então de suporte para a imagem fantasma. A questão é antes de saber como as emoções transformam-se em imagens metafóricas e quando elas entram no campo simbólico do ato físico da palavra e do ato social da comunicação sensorial.
\end{abstract}

Palavras-chave: imagem, midia, metáforas

\section{RÉSUMÉ}

La question de l'image et du médium nous ramène à la nécessité d'un support d'images, un "lieu des images", dans lequell'invisible (l'objet idée) et le visible (l'objet concret) forment une unité médiale à la recherche d'un sens. L'objet idée est une place virtuelle de vérité et la "méthaphore sensorielle" est l'identité d'une humanité détachée de l'élément de fascination exercé sur nous par la confrontation entre "l'image idée", "l'image fantasme" et "l'objet concret". Les "métaphores sensorielles" sont stockées de manière visible dans "l'Atelier d'images", quel que soit leur encadrement. L'image fantasme sort d'une matrice virtuelle (l'Atelier intime) en obligeant les fantasmes et les idées à développer de nouvelles modalités de perception et à réagir à de nouvelles techniques de représentation. Dans "I'Atelier d'images", l'objet concret sert alors de support pour l'image fantasme. La question est plutôt de savoir comme les émotions se sont transformées en images métaphoriques et quand elles sont entrées dans le champ symbolique de l'acte physique de la parole et de l'acte social de la communication sensorielle.

Mots-clés : image, médium, métaphoras

${ }^{1}$ D.E.A. em Filosofia da Existência no Centro Gaston Bachelard de Pesquisa sobre o imaginário e a racionalidade- Universidade da Borgonha-França. 


\section{Introdução}

Numa espécie de "ateliê íntimo", na espessura de uma fenda cavada no próprio ser e em face ao traço e materialidade do objeto no exterior, o desejo engendra a geométrica forma metafórica. Em cerimoniais nem sempre apraziveis, reconduzindo dissonâncias internas a percepções menos paradoxais, transformando toda complexidade numa multiplicidade obsessiva de questões, envolvendo-nos em negociações internas e externas; continuamente, o desejo cria e recria fantasias. E, na esperança de encontrar intervalos entre percepção, descrição e representação, esse mesmo desejo agenciado por essa máquina transformadora de emoções que é a nossa psique, conecta-se com as qualidades fictícias da imaginação e engendra o símbolo. $\mathrm{O}$ objetivo parece ser sempre o mesmo: o de apaziguar cóleras emocionais pela via de algo visual e estético.

No processo simbólico, uma "vontade", não necessariamente lógica, parece transformar aglomerações betuminosas de um mundo arcaico e oceânico, repleto de lama, terra, areia e cascalho, numa identidade de significação, antes longínqua da consciência. Nesse ponto, escavada de informes padrões arquetípicos, uma cidade imaginária começaria a surgir. Perspectivas novas se introduzem criando novos projetos mentais. Não haveria mais tanta dissonância entre o que é real e o que é imaginário. Quanto mais seduzidos fossemos pelos objetos no espaço, mais surgiriam "metáforas palpáveis", elemento fundamental para a manutenção de nossa máquina simbólica. Na verdade, essa "vontade" como queria Shopenhauer, essa "pulsão" como nos fala Freud, esse "desejo", como quer Lacan, ou, esses núcleos ou nódulos de energia virtual-arquetípico, como entende Jung, constituem a base conceitual para o entendimento e alargamento teórico necessário à exploração da mente pela via da linguagem verbal e da linguagem sensorial.

Sistemas pulsionais de imagens, metáforas racionais e imagéticas, imagens estéticas, imagens geométricas, ilusões, impressões, idéias e um mundo de coisas organizariam a nossa subjetividade muitas vezes em meio a uma desconfortável fragmentação da linguagem verbal. O recipiente mental em contato com a matéria bruta de nossa imaginação e num trabalho de arte, se veria obrigado a transformar os espaços e 
arranjos interiores, numa área de percepções imagéticas, instalando verdadeiros "ateliês intimos".

Tais ateliês fincados em bases arquetipicas serviriam de cenário interno para o Eu se constituir como o Senhor da consciência. No caos geológico de processos de integração e desintegração inconscientes, num refugo entre mente e matéria, seria produzida na ordem mais criativa possivel, uma lama mental pronta para ser refinada e subjetivada numa nova paisagem consciente. Nesse cenário, o cérebro operaria na fronteira entre a imago do objeto e o próprio objeto no exterior, claborando uma gramática concreta na própria ausência de materialidade de objetos "puros" e fechados, confrontando-os com materiais sólidos. Desse cmbate se produziria o lodo de um realismo metafísico, portador de condições de possibilidade de uma nova linguagem $\mathrm{c}$ de um objeto mais consistente para a práxis clínica $\mathrm{c}$ para a própria arte. Assim, uma investigação mais detalhada sobre o inconsciente seria processada instintivamente $\mathrm{c}$ tenderia a ultrapassar as barreiras da idéia de objeto e da linguagem verbal, por não se submeter a agonizante sintaxe do discurso racional oferecido pelo nosso convencional sistema de linguagem.

\section{Do "Atcliê Íntimo" ao "Ateliê de Imagens"}

A noção de "uso" é necessária para agregar o "Ateliê Íntimo" c ilusório ao aparato teórico c concreto necessário para a construção de sua réplica no exterior: o "Ateliê de Imagens". Esse "ateliê de Imagens" tenderia na direção de um "Laboratório de Imagens". Nesse "Laboratório de Imagens", imagens arquivadas instigariam os pesquisadores a desenvolver tcorias $\mathrm{c}$ a pensar sobrc o rcal, o simbólico e o imaginário a partir da percepção de novos planos como a textura, a cor, a superficie. Olhar a superficie inconsciente que se funde, dissolve e se encharca na materialidade de uma sintaxe que valoriza a metáfora física cscavada no solo firme do objeto material.

O psicólogo e pesquisador ao dar ênfase à materialidade do objeto converteriam o "objeto idéia" cm "Objcto do jogo", redimensionando, assim, os settings analíticos destituidos de organização manual. O "Ateliê de Imagens" ao possibilitar o contato do analista e do analisando com a matéria, evitaria o risco de se enveredar num trabalho clínico minimalista. Ao desenvolver a práxis 
clínica a partir exclusivamente de informações conceituais, lingüísticas, o analista muitas vezes se ver impedido de explorar de uma forma mais objetiva os problemas da linguagem sensório-afetiva-motora. No modelo tradicional da práxis clínica que valoriza apenas a linguagem verbal, a leitura de imagens fica confinada a uma paisagem artificial, com metáforas fracas. Nesse caso, o mapa mental está sempre condicionado ao "abismo infinito" de nossa imaginação. Já as descobertas psicológicas feitas pelo manuseio de materiais como a argila, tintas, tecidos, levam tanto o analista como o analisando ao "abismo físico" da matéria bruta.

Esse esforço em redimensionar através de "Ateliês de Imagens" os objetos semânticos e imaginários, preencheria o vazio deixado pela falta de materialidade do "objeto idéia", redimensionando a atividade clínica em psicologia. Aproximar o setting analítico de um "ateliê de imagens" àmplia as fronteiras da psicologia clínica unindo o plano do objeto idéia à pujança do objeto concreto, estabelecendo os parâmetros para a construção de uma nova linguagem verbal e simbólica. Como nos fala Gouvêa:

Sem dúvida, o lado sensorial do objeto pode vir a ser engolido pela idéia de "ausência". Percebemos que no nivel da práxis analítica essa concepção de um "objeto fantasma" acaba interferindo na práxis do analista. Analisar as pulsões destruidoras do analisando apenas no nível do verbal, acaba reduzindo a capacidade de simbolização do indivíduo. É que essas pulsões, inibidas em suas excitações sensoriais, não encontrariam um objeto consistente em que pudessem depositar a marca das emoções. Nesse caso, o analisando, ao se identificar com um objeto mutilidado (por ser só linguagem), confinar-seia em zonas difusas de um real que se lhe apresentaria sempre como vindo apenas do interior do sujeito. Nesse caso, o "desconhecido" do mundo externo seria negado em função do "desconhecido" do mundo interno, comprometendo o processo de tomada de consciência e construção do real." (GOUVÊA, 2000: 38)

Com base numa camada de energia pulsional e arquetípica e, sustentadas pelos objetos concretos no "ateliê de imagens", as 
geométricas produções do desejo se organizariam em torno de um processo estético e simbólico, cujas manifestações metafóricas se estruturariam num sistema imagético que valorizaria tanto a linguagem verbal quanto a linguagem sensorial. Nos "ateliês de imagens", sulcos geométricos poderiam ser cavados com o auxílio dessa fina ferramenta "a metáfora sensorial" e, assim, apreenderíamos em estado bruto, o aspecto físico da psicose ou da neurose'

Toda essa metamorfose envolveria necessariamente um trabalho dialético entre o mundo interno e o mundo externo, e seria amalgamada pela seguinte equação: psique $=$ desejo $=$ produção de imagens, metáforas e geometria.

\section{A máquina imaginária e o refinamento da matéria}

Somos também cientistas e parceiros ao tentar descobrir um método ou um raciocínio universal que seja válido, sobretudo para explicar o funcionamento desse misterioso psiquismo humano em suas intrincáveis relações com o mundo interno e com o mundo das coisas concretas.

Desde os primórdios o homem procura se espelhar na matéria e encontra nela a condição de possibilidade de dar uma forma às suas emoções e sentimentos. As imagens e as coisas são percebidas, transformadas em idéias de forma a criar um "olhar" sobre o funcionamento do universo como um todo.

A principio esse olhar foi mágico e se enraizava no problema ontológico: coisa, fenômeno e imagem/desejo. Mas aprendemos pela filosofia, pela arte, pela práxis clínica e pelas teorias psicológicas que a imagem não precisa estar colada à ontologia das substâncias para que seja reconhecida como realidade efetiva. Muitas vezes, a imagem/ desejo segue a forma da metáfora e se deixa substituir segundo o olhar do artista, do filósofo e do psicólogo.

Em sua essência a imagem/desejo é livre e essa liberdade produz diferentes "olhares" que dão ao homem o poder de criar uma ciência com consciência, alimentando o caráter multidisciplinar necessário ao novo espírito científico.

Como um beija-flor, a imagem/desejo é mensageira do sentido e critério determinante no discernimento da verdade. Geradora de metáforas ela é capaz de suplantar obstáculos epistemológicos, de ajudar 
na organização racional da experiência e de estabelecer ligações entre o desconhecido do mundo interno e o desconhecido do mundo das coisas.

Muitas vezes sem deixar nenhum traço, a imagem/desejo cria realidades metafóricas contra as grandes certezas sustentadas por racionalismos radicais ou pelos traumas da vida. Assim, cotidianamente humanizamos nosso desejo pela arte absoluta e tangível de uma sensibilidade metaforizada em imagens. A existência do artista em nós deve se conduzir pelos olhares da imaginação e pela práxis abundante dos traços criativos sugeridos pelos objetos.

\section{O olhar de Freud sobre a dinâmica da produção de imagens}

Também em Freud o principio fundamental de toda produção de imagem e de subjetividade está vinculado à noção de desejo. Freud em seu livro "A interpretação dos Sonhos" une a noção de desejo à noção de imagem. Em sua essência o desejo se definiria então como "produção de imagens". Aqui, para explicitar melhor o pensamento de Freud sobre a dinâmica do desejo na relação entre o sujeito e o objeto, 230 recorro à observação feita por ele ao comportamento de um de seus netos de dezoito meses. Refiro-me ao "fort-da" esse momento específico em torno da observação descrita por Freud em seu livro "Além do princípio do prazer".

Freud observara que o bebê tinha o hábito de jogar para longe pequenos objetos que casualmente lhe vinham às mãos. Segundo Freud, esse gesto era acompanhado pela criança com o som prolongado de oo-o-o-o, que, segundo Freud, constituía o esboço da palavra "fort" ("longe" em alemão). Num outro momento, essa mesma criança tem uma outra atitude que parecia mais completa: segurando na mão uma linha amarrada num carretel, o bebê arremessava o carretel para longe de seu berço dizendo o-o-o-o e, em seguida, habilmente, puxava o carretel de volta exclamando a palavra "da" - que em alemão quer dizer "eis aqui" ou "chegou".

Diria que essa pedagogia de substituição de objetos do desejo presentes no "fort-da" tem sido sempre a fórmula ideal encontrada pela psicanálise para demonstrạ a importância dos objetos concretos e do brincar como lugar ideal para a construção do tecido temporal da subjetividade. 
No "fort-da", o desejo da imagem e a imagem do desejo compõem o brincar necessário à fabricação do real. O carretel aparece como uma base fixa para as fantasias. Encontramos assim no "fortda" uma determinação evolutiva da imago do descjo que é transportada pelo afeto (libido) para a mãe. Segundo Freud, na ausência da mãe, essa libido é projetada no "objeto carretel", criando um espaço real para o fantasma do abandono.

Poderíamos então dizer que o carretel permitiu um corte na imaginação do bebê colocando em parênteses o desejo do bebê e, ao mesmo tempo, permitindo a criação de un correlato imaginário para a mãe real, preenchendo de certo modo o vazio deixado pela ausência. Grosso modo diria que no "fort-da" o desejo e a imagem se juntam às coisas criando no imaginário a condição de possibilidade da experiência sensório-afetivo-motora. Dessa forma as imagens têm cumprido o papel importante de criar formas elementares com o objetivo de instruir o espirito humano em sua tarefa de encontrar a "boa sintese". Como na metáfora, a imagem aparece como a solução mais adequada encontrada pelo desejo para veicular o sentido que escapa à lógica racional. Por trás da metáfora encontramos a "imagem-sentido" que nos permite lidar emocional c imageticamente com o mundo.

O desejo encontra na "metáfora viva" um instrumento eficaz de produção de sentido. Em sua maneira imagética de veicular o sentido a solução metafórica aparece como um esquema de transferência unificador em torno do qual o indivíduo se organiza c se estrutura. Ela nasce no vazio que se interpõe entre o sujeito e o objeto, entre o Eu e o mundo exterior e permite traduzir emoção em imagens.

\section{Sobre o ollarar a priori e o olhar a posteriori da imagem}

Poderíamos também, inspirando-se nas categorias kantianas, dizer que enquanto função psíquica e mensageira do desejo, a metáfora supõe uma dupla natureza de imagens: o a priori da imagem e o a posteriori da imagem. No a priori da imagem, o desejo mobiliza o olhar para dentro, criando o espaço interno (Ateliê Íntimo) para a interiorização do sentido. O objetivo é extrair a imagem de uma paisagem interna de emoções cuja substancialidade está sujeita às estranhezas das distorções fantasmáticas e inconscientes. 
A substancialidade dessas figuras ausentes busca a visibilidade através da emergềncia de formas imagéticas e de uma geometria apropriada ao sentido que se quer formular em múltiplas significações. Através de uma multiplicidade de imagens que dialogam entre si, se justapõem e se entrecruzam, a relação entre o visual e o verbal faz a passagem do ponto ao plano, do círculo à espiral, do imaginário ao real, da ficção à história, do jogo a uma poética impregnada de subjetividades.

Mas, esse olhar a priori da imagem supõe um segundo "olhar" mais atento aos objetos no espaço, na esperança de poder encarnar na determinação implícita de exterioridade presente nesses objetos fora, um suporte concreto para o fantasma (Ateliê de Imagens). O objetivo é garantir o desbloqueio e a dilatação aguda e formal do pensamento garantindo uma linguagem sensorial, engajando o pensamento e expandindo o circuito da arte para além do texto como obra. $O$ fator determinante nesse processo de atribuição sensorial à linguagem verbal, é a existência de úma sensorialidade garantida pela enfática presença de novos materiais. Tocar o desejo não apenas através de construtos ficcionais lingüísticos, redireciona a construção de nossa identidade a uma topografia móvel cujo valor subordina o diálogo e as reflexões teóricas a uma práxis cada vez mais ligada a um contexto histórico mais amplo. A lógica material dos objetos concretos força no inconsciente, o olhar a posteriori da imagem do desejo. Esse segundo olhar se interroga pelo mecanismo e funcionamento da matéria e cria no imaginário o desejo de concreção e pode ser explorado pelo "Ateliê de Imagens".

Numa dialética intermitente entre o a priori e o a posteriori da imagem, o desejo se fragmenta enfraquecendo-se enquanto uma dinâmica apenas visual. A percepção faz apelo a representações mais exatas e que se apliquem nas duas extremidades da experiência: tanto às idéias e às suas imagens ilusórias quanto, inversamente, à experiência sensivel com suas imagens palpáveis, antes banidas do campo da consciência.

O desejo anuncia então, pela fragmentação do olhar nessa dupla dimensão, a colocação em cena do mundo sensorial. Torna-se então vital para o ser a entrada no mundo das imagens sensoriais e não mais apenas imagens visuais. $O$ desejo se alinha pelas mãos que joga com os 
olhos na intricada teia dos fenômenos da natureza e sai em busca de um discurso que reenvia a idéia à abundância do dado sensível.

Numa alternância contínua entre a presença/ausência de objetos no espaço, os olhos e as mãos fabricam imagens e operam o desejo num discernimento demarcado pela conjunção "imagem sensorial e idéia". Trata-se de olhar a imagem pelo viés da imaginação sensorial. Ver duplamente: com o olhar dos olhos e o olhar das mãos. Assim, a partir do dado sensivel, a imagem cria um olhar para além da dimensão nostálgica e subjetiva do ser, deixando-se abordar por uma ontologia das substâncias materiais, reenviando o ser à realidade das coisas.

Diria que o olhar a priori é o olhar do sujeito e o olhar $a$ posteriori é o olhar do objeto. Contudo, não podemos esquecer que na origem ambos os olhares são olhares do sujeito. Mas a condição de possibilidade do homem vir a atingir o objeto do objeto, se encontra nessa dinâmica refratária desse duplo olhar em imagens.

Na verdade é o mundo das coisas que obrigou o homem a esse duplo olhar em imagens, e que também levaria Bachelard ao conceito de "Imaginação criativa" e "Imaginação reprodutora". A "imaginação reprodutora" é associada à memória e produz as imagens daquilo que percebemos, enquanto que a "imaginação criativa" produziria imagens daquilo que jamais percebemos. Contudo, a "imaginação reprodutora" está longe ainda de reproduzir o real em toda sua dimensão.

Seria no plano do imaginário que a potencia irreal da imagem mental vai se livrar, mesmo que de uma forma ainda precária, das amarras subjetivas do objeto idéia. Sendo assim, segundo Bachelard, a imagem literária nada mais é que o resultado da força imaginária em seu caráter de potência.

A imagem literária seria então uma reprodutora menos passiva do real. Contudo, na práxis clínica em que o analista usa objetos concretos como instrumental de trabalho analítico, seriam as imagens produzidas pelas mãos que seriam depositárias do desejo ativo de fabricação do real.

\section{Metáfora viva e metáfora sensorial}

A imaginação recorre à estratégia metafórica para mediar o sensivel e o inteligível. Ao funcionar como uma contra-imagem num 
sistema sensorial de representação - a metáfora aparece como a melhor solução para a produção do símbolo vivo.

Após retirar da linguagem falada o monopólio do sentido, o desejo dá vida à metáfora, criando na relação com o mundo dos objetos, a "metáfora sensorial". Através da metáfora sensorial presenciamos a destruição dos fundamentos exteriores da linguagem, de forma a criar uma espécie de simulacro do desejo. Esse simulacro ao invés de respeitar o desejo enquanto uma virtualidade no sujeito, adapta-se ao "desejo" dos objetos no mundo exterior, de forma a veicular o sentido numa produção imperfeita, enraizando-o numa dupla dimensão: ora lingüística e ora não lingüística.

Esse simulacro do desejo tem a função de reverter o mecanismo lógico presente na rede lingüística convencional, criando o sentido a partir do absurdo, de maneira a levar o indivíduo a duvidar do sentido apreendido pela lógica racional. O inconsciente aparece aqui como sendo algo que ultrapassa a máquina lingüística. Nesse caso, a subștância e o sentido que naturalmente nasce do desejo escapa ao domínio formal da lingüística saussuriana ainda que não sobreviva sem ela. Já, na rede 234 não-lingüística da metáfora sensorial, para que o racional e o lógico não sejam constantemente eliminados pelo processo metafórico, o desejo engendra, através de uma estética manual e por uma dinâmica própria, a modelagem como representação material do desejo. Assim, a imagem como uma solução material e palpável, reenvia o indivíduo, através de tensões e torções, a um conjunto de mutações objetivas antes em estado virtual.

Podemos então dizer que toda metáfora repousa sobre uma tensão capaz de causar torções no processo imaginativo. O conflito que gera essa tensão só pode ser elucidado em termos imagéticos. Isso porque a racionalidade das palavras não dá conta de veicular e exprimir o desejo sem antes recorrer à lógica imagética. $O$ enunciado que jaz por trás do desejo deve chegar à consciência, dever ser "transferido" para a consciência, mesmo que para isso seja necessário fazer uma torção na estrutura mesmo da linguagem.

Dessa torção necessária à produção da imagem do desejo e como uma possivel solução ao impasse criado pela necessidade de operar a junção entre o desconhecido do mundo de dentro e o desconhecido do mundo de fora - é que brota a "metáfora sensorial" como uma solução viva para o problema. Sua inovação principal é a de estabelecer uma 
ligação como a que fora estabelecida pelo neto de Freud quando metaforicamente procurou simbolizar sua mãe pelo carretel.

O racional e lógico da linguagem falada de certa forma são climinados nesse processo, formando um hiato no lugar. Exatamente nesse hiato o desejo enquanto algo que implica a dimensão social dos objetos no extcrior se identifica com o objeto concreto sc colocando, por assim dizer, no meio deles de forma a modelar uma imagem particular nesse hiato deixado pcla palavra.

Assim, na ausência do discurso uma imagem particular nasce desse vazio deixado pela palavra possibilitando o nascimento da "metáfora sensorial", do símbolo e do pensamento simbólico. Diriamos que o conflito, a tensão e o sentido que o inconsciente quer veicular ao consciente é que encaminhará as mãos na produção de um tipo de imagem que servirá para operar o desejo pela via da metáfora viva. Essa última como o próprio símbolo, supõe um jogo cuja intenção significante ultrapassa a linguagem falada c se prolonga $\mathrm{em}$ imagens sensoriais. Sendo assim, em sua função prospectiva c inovadora, como porta-voz do descjo e como geradora de sinteses, a metáfora sensorial opera o sentido $\mathrm{em}$ meio a objetos internos e objetos externos.

A partir das inúmeras imagens produzidas pela dinâmica metafórica do psiquismo, podemos perceber então que o desejo é quem costura a junção que se faz necessária entre csses dois tipos de representação: a "representação de sujeito" ligada ao objeto idéia e aos objetos imaginários e, a "representação de objeto" fruto de uma reprodução instantânea de traçados geométricos c curvos, capazes de produzir um sistema lógico de imagens sensoriais.

A metáfora sensorial aparece aqui como a condição de possibilidade de uma junção entre, a representação imaginada pelo desejo, e a temporalidade dos objetos no espaço. Pela representação de objcto o ser transitaria do ponto à espiral, dando origem à metáfora sensorial. Assim, poderiamos afirmar que o redondo, a espiral e o gcomćtrico são uma das variações dinâmicas de um mesmo descjo: o desejo de ser no mundo pela via dos objetos concretos.

A dimensão sensorial da metáfora é que possibilita modificar a imagem, de criar uma representação sensório-afetivo-motora e de petrificar o desejo graça a produção manual de imagens pela via dos objetos concretos. Portanto, o conceito de "metáfora sensorial" nos reenvia à junção de mutações sofridas pelo desejo, no momento em que 
tais mutações se metamorfoseiam em imagens geométricas, conferindo ao desejo um contorno espacial.

Não se trata mais de imaginar a imagem virtualmente, mas de registrá-la espacialmente possibilitando assim uma existência que lhe seja exterior. A imagem fabricada pelas mãos que manipulam a metáfora viva constitui uma fonte legítima para dar forma às nossas sensações, paixões e emoções, sem perder de vista o contexto social em que estamos inseridos. Nessa ótica é que podemos falar de "imaginação porosa" e de "metáfora sensorial", expressões que nos ajudam a encontrar uma superfície fixa para as fantasias.

Uma vez produzido o objeto do desejo em "metáforas sensoriais", tal objeto real sempre terá algo que o diferencia do objeto interno antes idealizado. A imagem metaforizada ao ganhár a dimensão espacial do objeto torce a torção inicialmente provocada pelo excesso de informações visuais e auditivas e, através de uma dinâmica manual toda particular, petrifica num objeto concreto a mensagem que anseia comunicar: Assim, a imagem metafórica é projetada em um objeto no espaço de forma a unificar a experiência subjetiva em torno de um 236 pólo unificador e fixo cujo principal objetivo é o de elaborar seu tecido temporal.

Enquanto uma produção do desejo a "metáfora sensorial" dá um traçado geométrico às representações virtuais e imagéticas, criando a dimensão sensório-afetivo-motora do desejo. Graças às determinações fenomenais advindas da "metáfora sensorial", o indivíduo consegue romper com registro virtual das imagens no inconsciente para em seguida reorganizar o imaginário seguindo combinações criadas a partir da mediação suplementar da matéria. Assim, o conteúdo a ser veiculado segue em busca de imagens, inovando através de mutações variáveis os fantasmas do desejo.

Certamente que através da imagem, o desejo no homem pode se coadunar ou não com o "desejo" da matéria e produzir o que conceituamos de "metáfora sensorial". Nessa perspectiva, diríamos que a "metáfora sensorial" é criada a partir da imagem sensorial produzida por traços sobre um suporte lingüístico estendendo-se, a seguir, sobre o suporte material dos objetos concretos. Nesse tipo de metáfora, as palavras e as imagens se revelam à idéia, através das semelhanças entre o objeto virtual do desejo e as representações sensoriais desse objeto. 
Concluindo, diríamos que a "metáfora sensorial" é uma "metáfora viva", mas nem sempre uma "metáfora viva" é uma "metáfora sensorial". Ambas pertencem na origem a uma dinâmica energética cujo desejo é o de veicular o Ser no mundo. Contudo, a "metáfora sensorial" possui uma função inovadora na medida em que ela deixa de copiar o sentido a ser veiculado para submetê-lo aos contornos do objeto concreto. Assim ela opera uma junção entre o desejo do espírito e a percepção enquanto uma idéia tirada subjetivamente do indivíduo e da própria coisa. Portanto, estaremos sempre a transitar do desejo da imagem a imagem do desejo pela via da "metáfora viva", da "metáfora sensorial" ou do "símbolo vivo". E, nessa dialética incessante incluímos os objetos e as coisas, coisas essas que devem sempre aparecer como uma existência exterior ao homem.

\section{Bibliografia}

BACHELARD, G. (1988). A poética do devaneio. São Paulo: Martins Fontes.

GOUVÊA, A. P. (2000). A Tridimensionalidade da Relação Analitica. São Paulo: Summus (2007). L'Univers Stellaire de Fernando Diniz. In

FIGURES No 30 - Imaginaire, art e thérapie - Cahiers sur "L'image, le Symbole et le Mythe". Dijon: Centre Gaston Bachelard.

(1990). Sol da Terra: o uso do barro em psicoterapia. São Paulo: Summus.

KANDINSKY, W. (1991). Point et ligne sur plan. Gallimard, Foliolessais.

\section{Notas}

' No artigo intitulado L'univers stellaire de Fernando Diniz (GOUVÊA, 2007: 7-20). explora-se a linguagem simbólica de Fernando Diniz c a de Kandinski a fim de compreender o eixo criativo da forma encontrada por ambos para analisar as emoções e os canais geométricos por onde essas emoções irradiam. Para Fernando Diniz, artista plástico brasileiro, internado como psicótico no Hospital Pedro II, "o geométrico ajuda a juntar as coisas". Através dos ateliês expressivos" do "Museu de imagens do inconsciente" Fernando consegue traduzir em imagens as emoções que o agitavam e, pensando sobre elas, ele tenta evitar ser dilacerado pelos conteúdos do 
inconsciente. Fernando parte das qualidades internas da cor e da linha "ondulada-geométrica" para compreender, de uma maneira um pouco mais consciente a estrutura da sua doença mental - a psicose. As séries de imagens produzidas por Fernando nos ateliês do "Museu de imagens do inconsciente" levaram psiquiatras e psicólogos a constatar que o traçado geométrico presente no trabalho do doente mental capta, como numa série de sonho, a atividade rítmica e criadora das imagens do inconsciente e permite repensar a relação entre a emoção e a escrita da emoção em imagens simbólicas. Morando no Hospital psiquiátrico e mergulhado em seu mundo de imagens, Fernando insiste em pintar estrelas. Um dia, a propósito de pinturas de estrelas ele acaba criando uma espécie de lenda sobre a origem das estrelas, talvez uma metáfora do mito de criação.Já, para Kandinsky existe uma vontade humana e imagética que procura encontrar um ponto de apoio, um núcleo comum para se expressar no mundo. Essa vontade se expressaria na forma do traço, da linha, das espirais, dos quadrados, dos círculos e de formas estelares. A produção da estrela estaria ligada ao poder que tem a linha de criar superfícies e produzir movimento. Kandinsky nos fala: "Esta estrela pode ficar cada vez mais densa, de modo que as interseções criem um centro mais apertado, no qual um ponto se forma e parece crescer. Esse ponto é o eixo ao redor do qual giram as linhas que podem finalmente se 238 confundir - uma nova forma nasce: uma superficie sob a forma definida do círculo". Essa descrição de Kandinsky no seu livro "Ponto e linha sobre plano" nos remete à dinâmica psicológica de Fernando e nos faz compreender a importância que tem o ponto, a linha para a construção das imagens no nosso imaginário. Essa maneira humana de produzir o simbólico está presente tanto nas pesquisas teóricas de Kandinsky como na luta de Fernando na busca do espaço cotidiano. No universo de Fernando, o homem aparece múltiplo, disperso e à procura de um espaço no mundo. Trata-se de um mundo emaranhado de música, ponto, plano, linhas, círculos, sílabas, espirais, mandalas, cores, geometria e palavras. Todo o universo estelar de Fernando está profundamente ligado a sua vida íntima, aos seus desejos e fracassos. Através de sua obra ele procura dar forma às emoções, num trabalho minucioso de reunificação progressiva de desejos e imagens. Ousamos mesmo dizer que há algo de Kandinsky em Fernando e de Fernando em Kandinsky. Fernando e Kandinsky vivem diferentes niveis de consciência. Mas, ambos querem compreender em profundidade o sentido e a significação dos conteúdos dos símbolos que chegam ao espírito, à imaginação e ao pensamento pela via do traço e das representações geométricas e esquemáticas. 


\section{Normas para publicação}

\section{Submissão de artigos}

Contracampo acolhe colaborações de autores do Brasil c do exterior, pertencentes ou não a programas de Comunicação. Os trabalhos submetidos são avaliados por dois pareceristas do Conselho Editorial e publicados após recomendação de ambos, obedecendo às datas de fechamento dos números semestrais. SOMENTE ARTIGOS INÉDITOS PODERÃO SER SUBMETIDOS A CONTRACAMPO.

\section{Formato e preparação de artigos para submissão}

Os trabalhos submetidos devem possuir entre 5000 a 7000 palavras, digitadas em Word (ou similar), fonte Times New Roman, corpo 11 c cspaçamento simples. O formato da página adotado para os trabalhos é o A4 $(21 \times 29.7 \mathrm{~cm}) \mathrm{com}$ as seguintes medidas: $2 \mathrm{~cm}$ de margem superior; $3 \mathrm{~cm}$ de margem inferior, $5 \mathrm{~cm}$ de margem esquerda, $3 \mathrm{~cm}$ de margem direita e medianiz 0 . Cabeçalho de $1,2 \mathrm{~cm}$ e rodapé de $1,6 \mathrm{~cm}$. Alinhamento pela esquerda somente. Todos os parágrafos devem ser indentados em $0.5 \mathrm{~cm}$.

\section{Título e autoria}

Fonte Artal. negrito, corpo 12, centrado e espacejamento entre linhas de 1,5 linhas. Usar caixa-alta (letra maiuscula) apenas para a primeira letra do título do artigo, cxceto para nomes próprios ou palavras que exijam o uso de caixa-alta por razòes gramaticais. O nome do autor deve ser colocado abaixo da última linha do título, centrado, em Arial, itálico, corpo 10. Se o artigo possuir mais de um autor, separar os nomes destes com um vírgula e espaço. O nome de cada autor deve estar na seguinte ordem: primeiro nome, segundo nome ou inicial (se for o caso) c o sobrenome. Incluir no final da primcira página do artigo nota de rodapé (com entrada após o sobrenome de cada autor, numcração personalizada por asterisco) com dados biográficos sobre o(s) autor(cs), constante de filliação institucional, titulação, e-mail para contato etc. com cerca de 50 palavras, em fontc Arial, regular, corpo 9.

\section{Palavras-chave e resumos}

As palavras-chaves ( 3 a 5) e resumo devem vir após o titulo c os autores, com fonte Arial, corpo 10. Estas devem ser colocadas depois do resumo e serem antecedidas da palavra: "Palavras-chaves". O resumo deve ter aproximadamente 150 palavras. As especilicações para parágrafo e coluna são as mesmas do corpo do texto. O resumo deve ter como título a palavra "RESUMO", alinhada à esquerda, em Arial negrito, corpo 10. Na linha seguinte coloque o texto do resumo. As palavras-chaves e resumo em inglès devem observar o mesmo formato para o portugues. Devem vir após o resumo em português. Substituir os titulos: "Palavras-chaves" por "Keyivords" e "Resumo" por "Abstract", para as palavras-chaves e resumo em inglês. O texto do artigo deve ser iniciado na página scguinte às palavras-chaves (keywords) c ao resumo (abstract) em inglès. Não inserir numeração nas páginas e nem quebra de página. 


\section{Imagens}

Para o envio de material fotográfico, os editores devem ser previamente contatados para maiores especificações.

\section{Citações}

Para citar um autor no corpo do texto use 'aspas simples'. Citações que excedam três linhas devem ser separadas do corpo do texto (aperte a tecla

'enter' uma vez). Para citações, usar fonte Times New Romam, regular, corpo 10 , alinhamento à esquerda. Espacejamento entre linhas deve ser simples, recuo de parágrafo de $0,5 \mathrm{~cm}$, e espaço de 6 pontos após cada parágrafo de sua citação (se for o caso).

\section{Notas e Referências}

Usar notas de final de documento apenas, com exceção da nota biográfica do(s) autor, que aparece na primeira página do artigo. Usar fonte Times New Roman, regular, corpo 9; e alinhar o texto pela esquerda. Usar notas de rodapé quando absolutamente necessário e evitar notas longas.

As referências bibliográficas devem vir logo após a seção de notas e seguir a NBR 6023 DA ABNT, observado o formato de margens e espaços definidos acima. Todas as referências devem vir listadas alfabeticamente e cronologicamente na seção de referências, sob o título "Referências" (ver especificações para títulos de primeiro nível). Para formatar as referências use fonte Times New Roman, regular, corpo 12, alinhamento à esquerda, espacejamento simples entre linhas, recuo especial de $0,5 \mathrm{~cm}$ da segunda linha em diante e espaço de parágrafo de 6 pontos após cada referência.

\section{Considerações sobre direitos autorais}

Os artigos submetidos devem vir acompanhados de autorização de publicação pelo autor. Contracampo detém o copyright sobre o conteúdo da publicação aceita." Fotocópias de artigos são autorizadas mediante solicitação aos editores e crédito das fontes. Para evitar violação das leis de direitos autorais, favor não utilizar longas e muitas citações de uma mesma fonte, ou figuras publicadas previamente sem um documento de autorização de uso dos direitos autorais. Isto também se refere a imagens produzidas pelo autor, publicadas em outro veículo, cujo direito autoral tenha sido transferido à editora referente ao veículo anterior. Autores que não fornecerem documentos de autorizaçã́o de uso de direitos autorais terão seus artigos devolvidos.

\section{Envio de artigos:}

Os originais deverão ser enviados em três cópias impressas, acompanhadas de CD, para o seguinte endereço: Rua Tiradentes, 148 , Ingá, Niterói CEP: 24270 240 , Rio de Janeiro- RJ

Contracampo - Uma revista financiada pelo programa PROAP/CAPES. e-mail para contato: felipepena@globo.com. Editor-chefe: Prof. Dr. Felipe Pena 


\section{Contracampo}

Pensar la cultura con y después de Bourdieu

Rossana Reguillo

Influências européias no cinema gaúcho urbano

Carlos Gerbase

Entrevista: Prof. François Jost (diretor do CEISME - Université de Paris III) Felipe Pena e Itania Gomes

Jornalismo e modelos de mulher: a construção de sentidos das narradoras de TPM Márcia Benetti e Patrícia Rocha

"O jornalismo está morto, viva o jornalismo!": reflexões sobre usos e práticas de comunicação

Ana L.Enne

Uma proposta para a análise da identidade de marca dos canais de televisão brasileiros

Adriano Sampaio

Habermas e a Teoria do Jornalismo: a manipulação ideológica no jornalismo como distorção sistemática da comunicação

Heitor Costa Lima da Rocha

Sobre a produção de subjetividade na atual sociedade do espetáculo

Carlos Augusto Peixoto Junior

Lições da aula, Roland Barthes, professor no Collége de France

Latuf Isaias Mucci

A imaginação no poder: o teatro da política na encenação da legitimidade André Azevedo da Fonseca

O Big Brother Brasil e as formas contemporâneas de subjetividade Bernardo Jablonski e Erika L. Lazary

Nós, sujeitos autobiógracos: uma história de narradores, romancistas e 'cineastas do Eu'

Julio Bezerra

A imagem como metáfora do desejo

Alvaro de Pinheiro Gouvêa

1 - SEMESTRE 2007 